\title{
THE PERSONALITIES OF SIGNIFICANT OTHERS IN ASSOCIATION WITH REGULAR DRINKING IN ADOLESCENCE
}

\author{
Georgi M. Sarov \\ Department of Pathophysiology, \\ Medical Faculty, \\ Trakia University, \\ Stara Zagora, \\ Bulgaria
}

\author{
Corresponding author: \\ Georgi M. Sarov \\ Medical Faculty, Trakia University \\ 11, Armeiska Str. \\ Stara Zagora, 6003 \\ Bulgaria \\ e-mail:sarov@yahoo.com
}

Received: February 18, 2016

Revision received: March 25, 2016

Accepted: May 30, 2016

\begin{abstract}
Summary
It is well known that some psychological features of adolescents are positively associated with alcohol drinking but less attention is paid to the psychological features of their significant others. The aim of the study was to describe a common psychological profile of significant others to regularly alcohol drinking adolescents. A survey was conducted using an original questionnaire, which classifying alcohol drinking as regular, social (incidental) and abstinence. Of 903 students (aged 15-19), 169 identified themselves as regular drinkers (RDA) and 279 - as abstainers (NDA). The significant others of these two groups were compared statistically in terms of a wide range of psychological features. It was found that RDAs were significantly more likely to have: fathers $(\mathrm{OR}=1.94 ; 95 \% \mathrm{CI} 1.04-3.62)$ and friends (OR $=1.55 ; 95 \% \mathrm{CI} 1.02-2.36)$ that tended to avoid obligations in favor of pleasure; extravert friends $(\mathrm{OR}=1.55 ; 95 \% \mathrm{CI} 1.06-2.28)$ and lovers $(\mathrm{OR}=1.72 ; 95 \%$ CI 1.14-2.59); impulsive lovers (OR $=1.76$; $95 \%$ CI 2.86 $1.08)$, and obeying $(\mathrm{OR}=1.95 ; 95 \% \mathrm{CI} 1.01-3.80)$ friends; conventional fathers $(\mathrm{OR}=2.17 ; 95 \% \mathrm{CI} 1.27-3.72)$ and less likely to have independent mothers $(\mathrm{OR}=0.57 ; 95 \%$ CI 0.32-0.99) and hardworking friends $(\mathrm{OR}=0.58 ; 0.35$ 0.95 ). It seems that significant others of RDAs are less likely to exhibit models of rational reactions in everyday life that prevent adolescents from developing rational personality, thus making it possible to increase the probability of regular drinking in adolescence.
\end{abstract}

Key words: significant others, personality, alcohol, adolescence

\section{Introduction}

Many investigations have found association between adolescents' drinking and risky behavior of significant others [1-6] but little is known about the role of significant others' personality in association with alcohol use in adolescence.

Personality is a questionable matter in psychology and basic psychological theories are not primarily designed to explain personality in connection with alcohol use. Although, in confirmation of the psychoanalytic strategy $[7,8]$, numerous investigations have found association between sexuality and alcohol use [9-12]. 
Association of impulsivity [13-17] and extraversion [18] with alcohol use confirms dispositional strategy. Behaviorists emphasise the role of significant others in terms of social learning [19-21] and social control [22-25] theories and penomenologists lay stress on the role of self-control [26].

In a previous work [27] we introduced a threedimensional model that interprets personality as an individual combination of three motivational streams: egocentric, conformist and transcendental. We found a positive association between egocentrism and adolescents' regular alcohol drinking. The aim of this article was to investigate the role of significant others' personality in adolescents' alcohol drinking in terms of the three-dimensional model.

\section{Patients and Methods}

\section{Conception}

The three-dimensional personality views psyche as bonded with three-dimensional reality: biological, dialectical and transcendent. Events arising in the body become conscious as needs and form the core of egocentric concept about the live-need satisfaction. Events in the interactive sphere are conditionally bonded with the ego ego will receive what is needed only if this is expected, so the core of conformist concept is consideration of other acting actors and things. The transcendental world consists of relationships that may convert into real interactions and the main transcendental concept is chance control by actions based on knowledge about natural and social laws. The threedimensional personal strategy is an individual imaginary definition about the essence of a situation and as a consequence - the right actions in this situation. Egoists tend to define all the situations as egocentric and their consciousness is occupied with satisfying needs. Conformists tend to see the world as dialectic matter and their minds are occupied with the necessity to counterreact adequately. Idealists predominantly perceive life as a consequence of transcendental laws and are determined to follow the rules. In this context, risky behavior may be biologically and socially motivated although it is transcendentally bad and egocentrics and conformists should be motivated to drink alcohol more that idealists. However, it is not clear how different personal concepts will interact and how significant others' personalities will impact adolescents' drinking behavior. The aim of this article was personality description of significant others to regularly alcohol drinking adolescents.

\section{Measurements}

We developed a self-reported questionnaire for self-evaluation by means of adjectives and preferred statements [27]. Ego drive was indicated by statements and adjectives confirming the leading role of the ego in the form of hedonism (likes pleasant experiences, delicious food and pleasures of life) and impulsivity (impulsive and emotional; easily changes desires; easily changes mood; disorganized, scattered, unmotivated). Conformists were indicated as conventional (religious, sincere believer; conventional, predictable, uniform person), and sociable (cannot bear to be alone, likes parties and merriment; reclusive, strange). Idealists was indicated as rational (smart, clever, an erudite; calm, reasonable, thoughtful; persevering in the pursuit of goals; standing in goals) and commited (ambitious, hardworking, exhausted, disorganized, scattered, unmotivated; on achievement of one goal, there is as switch to another), and antisocial (prefers to be alone). Additionally, several statements and adjectives were introduced to reveal contradictions between the three concepts: transcendental rejection (pleasure first, then what is necessary), authoritative attitudes (prefers to lead; prefers to obey; prefers to be autonomous and independent), social control-providing abilities (handsome, charming, sexy; glamorous; pleasant, friendly, cheerful; original and intriguing; convincing), moral attitudes (not tolerating refusal or objections, being defeated or underestimated; selfish, stubborn, unyielding; unjust, unfair, grumpy; principled, fair; good, caring, generous). In order to reveal which concept was most successful, some adjectives and statements about effectiveness of behavior were introduced: self-efficacy (successful, prosperous; unsure), self-esteem (vital, energetic, motivated; nervous, irritable, aggressive; depressed or desperate).

\section{Study design}

All students from $9^{\text {th }}$ to $12^{\text {th }}$ grades (16-19 aged) in three secondary schools of Stara Zagora, Bulgaria were invited to participate in the survey. The study protocol was approved by the Ethics Committee for Clinical Research of the Medical Faculty, Trakia University, Stara Zagora, Bulgaria and the Regional Inspectorate of the 
Ministry of Education of Bulgaria. To increase the response rate, the survey was conducted in class hours in cooperation with the school authorities. The students were placed in large rooms, seated at sufficient distance from each other to provide independent and anonymous answers to the questions. To provide maximum reliability of the data, the responses were collected in a sealed urn and each student was free to refuse participation.

\section{Participants}

A total of 1077 students were invited to participate in this study. Of these, 1051 accepted to participate and 903 filled out the questionnaire correctly (response rate: $83.8 \%$ ). According to their answers, 169 students (18.72\%) were identified as regular alcohol drinkers (RDA), and $279(30.9 \%)$ - as abstainers (NDA).

\section{Data analysis}

We applied descriptive statistics, Chi-square test and logistic regression for statistical comparison between the RDA and NDA groups. The data were calculated by means of statistic software product SPSS.

\section{Results}

The significant differences between RDA and NDA significant others are shown in Table 1. RDAs were more likely to perceive their fathers as conventional $(\mathrm{OR}=2.17)$ and transcendence ignoring $(\mathrm{OR}=1.94)$ persons. They were more likely to describe their mothers as introvert $(\mathrm{OR}=3.24)$ persons and less likely - as independent ones $(\mathrm{OR}=0.57)$. RDAs were more likely to describe their beloved persons as pleasure oriented $(\mathrm{OR}=1.59)$, impulsive $(\mathrm{OR}=1.76)$, disorganized $(\mathrm{OR}=2.68)$, and extravert $(\mathrm{OR}=1.72)$ ones. RDAs were more likely to think that their friends were extraverts $(\mathrm{OR}=1.55)$, ones that prefer to obey $(\mathrm{OR}=1.95)$ and postpone obligations in favor of pleasures $(\mathrm{OR}=1.55)$ and less likely that they were hardworking persons $(\mathrm{OR}=0.58)$.

Table 1. Significant differences in personality of significant others of RDAs and NDAs

\begin{tabular}{|c|c|c|c|c|c|}
\hline & $\begin{array}{l}\text { RDA (n=169) } \\
\%(\mathrm{SE})\end{array}$ & $\begin{array}{l}\text { NDA }(n=279) \\
\%(\mathrm{SE})\end{array}$ & $\mathrm{p}<$ & OR & $95 \% \mathrm{CI}$ \\
\hline \multicolumn{6}{|l|}{ My father: } \\
\hline Conventional, predictable, uniform & $20.12 \pm 3.08$ & $10.39 \pm 1.83$ & 0.01 & 2.17 & $1.27-3.72$ \\
\hline One of his rules is: „Pleasure first, then what is necessary” & $13.61 \pm 2.64$ & $7.53 \pm 1.58$ & 0.05 & 1.94 & $1.04-3.62$ \\
\hline \multicolumn{6}{|l|}{ My mother: } \\
\hline Reclusive, strange person, prefers to be alone & $7.69 \pm 2.05$ & $2.51 \pm 0.94$ & 0.05 & 3.24 & $1.27-8.29$ \\
\hline Prefers to be autonomous and independent & $11.24 \pm 2.43$ & $18.28 \pm 2.31$ & 0.05 & 0.57 & $0.32-0.99$ \\
\hline \multicolumn{6}{|l|}{ My beloved person: } \\
\hline Likes pleasant experiences, delicious food and the pleasures of life & $48.80 \pm 3.88$ & $37.45 \pm 3.16$ & 0.05 & 1.59 & $2.38-1.06$ \\
\hline Impulsive and emotional & $25.90 \pm 3.40$ & $16.60 \pm 2.43$ & 0.05 & 1.76 & $2.86-1.08$ \\
\hline Disorganized, scattered, unmotivated & $9.64 \pm 2.29$ & $3.83 \pm 1.25$ & 0.05 & 2.68 & $6.22-1.15$ \\
\hline Cannot bear to be alone, likes parties and merriment & $37.87 \pm 3.73$ & $26.16 \pm 2.63$ & 0.01 & 1.72 & $1.14-2.59$ \\
\hline \multicolumn{6}{|l|}{ My friends: } \\
\hline Cannot bear to be alone, like parties and merriment & $55.03 \pm 3.83$ & $44.09 \pm 2.97$ & 0.05 & 1.55 & $1.06-2.28$ \\
\hline Prefer to obey & $11.83 \pm 2.48$ & $6.45 \pm 1.47$ & 0.05 & 1.95 & $1.01-3.80$ \\
\hline Hardworking & $15.38 \pm 2.78$ & $24.01 \pm 2.56$ & 0.05 & 0.58 & $0.35-0.95$ \\
\hline One of their rules is: „Pleasure first, then what is necessary” & $33.73 \pm 3.64$ & $24.73 \pm 2.58$ & 0.05 & 1.55 & $1.02-2.36$ \\
\hline
\end{tabular}

\section{Discussion}

The role of significant others in alcohol drinking in adolescence has been the subject of many articles [1-6, 28, 29], but mainly in the context of social learning [19-21], social control [22-25] and personal dispositions [13-18]. Less attention has been paid to connections between adolescents' alcohol consumption and significant others' personalities. In this study, it was found that some personality traits of significant others were related to regular alcohol drinking. It was revealed that RDAs came from families characterized by transcendence-ignoring 
conventional fathers and poorly communicative and independent mothers. When combined, these characteristics suggest insufficient level of communication about transcendence and correct intimate relations, i.e. topics very important for adolescents. Without such instructive support, adolescents should rely on other sources of information (peers) and their own experience and intuition. As we found in our previous work [27] RDAs could be classified as egocentrics in a three-dimensional model of personality (3DMP) with increased motive of power and transcendental ignorance. Such personal profile could be a result of instructional insufficiency in the family and may suggest the context of lovers and friends selection. The personalities of RDAs' lovers were characterized by egocentric traits similar to those we found in RDAs: impulsivity, disorganization and pleasure-orientation [27]. These traits could be also attributed to spontaneous, uncultivated human nature without transcendental „encumbrances”. Transcendence neglecting of RDAs (postponing obligations in favor of pleasure) could be also seen in the description of friends' personalities, but instead of fully ,replicate" personality of lovers, friends seem to ,add" personality, and while RDAs prefer to dominate [27], their friends prefer to obey.

This is the first application of the threedimensional model of personality to explain the role of significant others in adolescent alcohol drinking. It adds a new perspective to social learning and social control theories. At present, it is hard to say how productive this new approach will be, as additional confirmations are needed. Yet we insist that personal interactions in the 3D vision are much easier to change by education and psychological help than in social-cognitive models, ego drives and personal dispositions. Education in adolescence should just add instructions that are lacking, thus helping with personality construction, and build transcendental perspective in order to establish proper self-control for alcohol prevention.

\section{Conclusions}

According to data, the personal relations with significant others that increase the chance of adolescents to become regular drinkers could be classified as determining and selective.

Determining relations come from parents and form an adolescent's personality. In this regard, transcendental reality and proper intimate relations (love) allows for spontaneous personality development without cultivation and predisposes to the development of egocentric personality.

Selective relations are the result from the selection of complementary personalities among peers (friends and lovers) that allow for achieving personal completeness. In this regard, lovers function as "similar, same level person" and friends - as „willing to complement, lower level person". Extraversion is a common trait in this adolescent circle of dependences, maybe because of shared incompleteness of personality. Against this psycho-social background, alcohol may function as an additional interpersonal bond, strengthening the insufficient depth of interpersonal relations.

\section{Acknowledgements}

This study was supported by an institutional research grant at Medical Faculty, Trakia University, Stara Zagora, Bulgaria (grant number 31/2014).

Thanks to Dr. Galya Chamova from Department of Social Medicine and Healthcare Management, Medical Faculty, Stara Zagora, for her contribution to statistical analysis.

\section{References}

1. Eitle D. The moderating effects of peer substance use on the family structure-adolescent substance use association: Quantity versus quality of parenting. Addict Behav. 2005;30:963-80.

2. Latendresse SJ, Rose RJ, Viken RJ, Pulkkinen L, Kaprio J, Dick DM. Parenting mechanisms in links between parents' and adolescents' alcohol use behaviors. Alcohol Clin Exp Res. 2008;32(2):322-30.

3. Pettersson C, Lindén-Boström M, Eriksson C. Parental attitudes and behavior concerning youth alcohol consumption: do sociodemographic factors matter? Scand J Public Health. 2009;37:509-17.

4. Schulenberg J, Maggs JL, Dielman TE, Leech SL, Kloska DD, Laetz VB. On peer influences to get drunk: A panel study of young adolescents. Merrill-Palmer Quart. 1999;45:108-42.

5. Swadi H. Individual risk factors for adolescent substance use. Drug Alcohol Depend. 1999;55:209-24.

6. Urberg KA, Deg irmenciog lu SM, Pilgrim C. Close friend and group influence on adolescent 
cigarette smoking and alcohol use. Dev Psychol. 1997;33:834-44.

7. Freud S. New Introductory Lectures on Psychoanalysis. New York: W W Norton \& Co; 1933.

8. Freud S. Das Ich und das Es. Leipzig, Vienna, and Zurich: Internationaler Psycho-analytischer Verlag; 1923.

9. Mason WA, Hitch JE, Kosterman R, McCarty CA, Herrenkohl TI, Hawkins JD. Growth in adolescent delinquency and alcohol use in relation to young adult crime, alcohol use disorders, and risky sex: a comparison of youth from low-versus middleincome backgrounds. J Child Psychol Psyc. 2010;51(12):1377-85.

10. Rothman EF, Wise LA, Bernstein E, Bernstein J. The timing of alcohol use and sexual initiation among a sample of Black, Hispanic, and White adolescents. J Ethn Subst Abuse. 2009;8(2):12945.

11. Stueve A, O'Donnell LN. Early alcohol initiation and subsequent sexual and alcohol risk behaviors among urban youths. Am J Public Health. 2005;95(5):887-93.

12. Seth P, Sales JM, DiClemente RJ, Wingood GM, Rose E, Patel SN. Longitudinal examination of alcohol use: a predictor of risky sexual behavior and Trichomonas vaginalis among AfricanAmerican female adolescents. Sex Transm Dis. 2011;38(2):96-101.

13. James LM, Taylor J. Impulsivity and negative emotionality associated with substance use problems and Cluster B personality in college students. Addict Behav. 2007;32:714-27.

14. MacKillop J, Mattson RE, MacKillop EJA. Multidimensional assessment of impulsivity in undergraduate hazardous drinkers and controls. Alcohol. 2007;68:785-8.

15. Magid V, Colder CR. The UPPS Impulsive Behavior Scale: Factor structure and associations with college drinking. Pers Indiv Diff. 2007;43:1927-37.

16. Simons, JS, Carey KB, Gaher RM. Lability and impulsivity synergistically increase risk for alcohol-related problems. Am J Drug Alcohol Ab. 2004;30:685-94.

17. McGue M, Iacono WG, Legrand LN, Malone S, Elkins I. Origins and consequences of age at first drink. I. Associations with substance-use disorders, disinhibitory behavior and psychopathology, and P3 amplitude. Alcohol Clin Exp Res. 2001;25:1156-65.
18. Fleming JP, Kellam SG, Brown CH. Early predictors of age at first use of alcohol, marijuana, and cigarettes. Drug Alcohol Depend. 1982;9:285303.

19. Goldman MS, Brown SA, Christiansen BA, Smith GT. Alcoholism and memory: Broadening the scope of alcohol-expectancy research. Psychol Bull. 1991;110:137-46.

20. Chassin L, Curran PJ, Hussong AM, Colder CR. The relation of parent alcoholism to adolescent substance use: A longitudinal follow-up study. J Abnorm Psychol. 1996;105:70-80.

21. White HR, Johnson V, Buyske S. Parental modeling and parenting behavior effects on offspring alcohol and cigarette use: A growth curve analysis. J Subst Abuse. 2000;12:287-310.

22. Chassin L, Hussong A, Barrera M Jr, Molina BSG, Trim R, Ritter J. Adolescent substance use. In: Lerner RM, Steinberg L, editors. Handbook of adolescent psychology. 2nd ed. Hoboken (NJ): John Wiley \& Sons, Inc.; 2004. p. 665-96.

23. Barnes GM, Reifman AS, Farrell MP, Dintcheff BA. The effects of parenting on the development of adolescent alcohol misuse: A six-wave latent growth model. J Marriage Fam. 2000;62:175-86.

24. Jackson C, Henriksen L, Dickinson D. Alcoholspecific socialization, parenting behaviors, and alcohol use by children. J Stud Alcohol. 1999;60:362-7.

25. Jones DJ, Forehand R, Brody G, Armistead L. Parental monitoring in African American, single motherheaded families. Behav Modif. 2003;27:435-57.

26. Schomerus G, Corrigan PW, Klauer T, Kuwert P, Freyberger HJ, Lucht M. Self-stigma in alcohol dependence: consequences for drinking-refusal self-efficacy. Drug Alcohol Depend. 2011;114(1):12-7.

27. Sarov GM. Attitudes of regular alcohol drinking adolescents to intersubjective relations and everyday life. J Biomed Clin Res. 2014;7(2):141-7.

28. Chamova $\mathrm{G}$. [The role of significant others for risk cluster formation in regularly drinking adolescents]. Soc Med (Sofia). 2014;2:22-4. Bulgarian.

29. Chamova G. [Psychosocial determinants of risk behavior in adolescence]. Soc Med (Sofia). 2012;4:4-7. Bulgarian. 